\title{
The importance of epigenetic factors for the diagnostics and treatment of type 2 diabetes mellitus
}

\section{ABSTRACT}

The level of expression of certain genes modifying the phenotype may affect the progression of diabetes mellitus and its complications. Gene expression is controlled by epigenetic modifications, influenced by intracellular and environmental factors, e.g. nutrition model and physical activity. These modifications appear throughout whole life, from conception until the time of death, and they are closely dependent on cell differentiation, DNA repair and cellular stress. Hopefully, the knowledge of epigenetics might be used in the future as an element of personalized treatment of diabetes.

The following article aims to review the most important mechanisms of epigenetic modifications in context of pathogenesis and pathophysiology of type 2 diabetes mellitus. (Clin Diabetol 2018; 7, 3: 164-170)

Key words: epigenetics, type 2 diabetes mellitus, metabolic memory, intergenerational transmission

\section{Introduction}

Epigenetics is a term that appeared in the 1940s, and this concept gained popularity along with the development of molecular biology. In the original sense, epigenetics is a branch of biology dealing with

Address for correspondence:

mgr farm. Agnieszka Stelmaszyk

Katedra i Zakład Farmakologii

Uniwersytet Medyczny im. Karola Marcinkowskiego w Poznaniu

ul. Rokietnicka 5A, 60-806 Poznań

Phone: 6185472 62, fax: 618547252

e-mail: stelmaszyk.agnieszka@gmail.com

Translation: lek. Małgorzata Kamińska

Clinical Diabetology 2018, 7, 3, 164-170

DOI: $10.5603 /$ DK.2018.0013

Received: 14.01.2018

Accepted: 20.02 .2018 cause-and-effect relationships between genes and their products that determine the phenotype of the organism [1]. The field of interest of epigenetics is both the mechanism of modulation of gene expression and the possibility of inheritance of expression patterns by daughter cells that result from mitotic or meiotic division [1]. Hence another, popular definition of epigenetics emphasizes that the focus of epigenetic research are changes in gene function acquired as a result of mitotic and/or meiotic processes, which cannot be explained and justified by changes in the DNA sequence $[2,3]$.

Gene expression is controlled by both intracellular and environmental factors (nutrition, physical activity). These modifications appear throughout whole life, from conception until the time of death, and they are closely dependent on cell differentiation, DNA repair and cellular stress $[3,4]$.

At the cellular level, epigenetic information is mainly reflected by the modification of histones, by the degree of DNA methylation and by the expression of micro-RNA (miRNA) $[1,5,6]$.

The function of strongly basic histone proteins inside the cell is associated primarily with the formation of nucleosomes that are structural chromatin subunits in the nucleus. Histones undergo post-translational reversible modification, e.g. by acetylation. Generally, epigenetic histone modifications are short-lived and reversible [7].

Acetylation or deacetylation most frequently occurs at the $\mathrm{N}$-terminal lysine residue of histone. Acetylation is associated with the loss of positive charges on the surface of the histone molecule, thereby reduction the interaction between histone proteins and negatively charged DNA phosphate groups, leading to the relaxation of the chromatin structure, and in consequence facilitating the transcription process [7]. 
Table 1. Selected enzymes catalyzing epigenetic histone modifications

\begin{tabular}{|c|c|c|}
\hline Group of enzymes & Exemplary enzymes & Type of modification \\
\hline \multirow[t]{4}{*}{$\begin{array}{l}\text { Histone acetyltransferases } \\
\text { (HAT) }\end{array}$} & $\begin{array}{l}\text { GNAT superfamily: Gcn5, PCAF, Hat1, } \\
\text { Elp3, Hpa2 [36] }\end{array}$ & \multirow[t]{4}{*}{$\begin{array}{l}\text { Lysine acetylation [37], maintenance of euchromatin } \\
\text { structure, increase in gene expression [38] }\end{array}$} \\
\hline & MYST superfamily: Sas2, Sas3, Esa1, & \\
\hline & MOF, Tip60, MOZ, MORF, HBO1 [36] & \\
\hline & p300/CBP [36] & \\
\hline \multirow[t]{4}{*}{ Histone deacetylases (HDAC) } & Class I: HDAC1-3, HDAC8 [39] & \multirow{4}{*}{$\begin{array}{l}\text { Lysine deacylation, maintenance of heterochromatin } \\
\text { structure, reduction in gene expression [38] }\end{array}$} \\
\hline & Class II: HDAC4-7, HDAC9-10 [39] & \\
\hline & Class III: SIRT1-7 [39] & \\
\hline & Class IV: HDAC11 [39] & \\
\hline \multirow[t]{3}{*}{ Methyltransferases } & Nuclear receptor protein containing & Lysine methylation, e.g.: \\
\hline & SET7 domain [24] & - Lys9 of histone $\mathrm{H} 3$ - reduction in gene expression \\
\hline & & - Lys4 of histone H3 - increase in gene expression [38] \\
\hline Histone demethylases & Lysine-specific histone demethylase 1 [28] & Lysine demethylation [28] \\
\hline (HMTases) & Jumonji C [28] & \\
\hline
\end{tabular}

Table 2. Selected enzymes catalyzing epigenetic DNA modifications

\begin{tabular}{lll}
\hline Group of enzymes & Exemplary enzymes & Type of modification \\
\hline DNA-methyltransferases (DNMT) & DNMT1 - "recognizes" the methylation pattern & Methylation of the nucleobases, most \\
& of the parent DNA strand and reconstructs it on & frequently cytosine [37] \\
& the de novo synthesized strand [38] \\
& DNMT3a and DNMT3b - methyltransferases \\
& introducing methyl residues to previously \\
& unmodified CpG islands [38] \\
\hline
\end{tabular}

Histone changes are not limited to acetylation or deacetylation and can be more diverse. They also include phosphorylation and dephosphorylation, isomerization, and attachment or detachment of ubiquitin or small ubiquitin-like modifier proteins (SUMO). The covalent modification of histone determines the ability of chromatin to convert to a transcriptionally active state. Histone modifications are catalyzed by pairs of enzymes with converse activity [8]. Some of them are characterized in Table 1.

DNA methylation, unlike histone protein modifications, is a more permanent change, causes long-term effects, and can also be inherited by daughter cells [8]. Selected DNA-methyltransferases that catalyze the attachment of the methyl group, most commonly at the C-5 position of cytosine in the DNA molecule, are listed in Table 2 . The methylation process most often relates to DNA nucleotide sequences called CpG (Cytosine-phosphate-Guanine) island. Methylation of CpG islands leads to a reduction in gene expression — "silencing" [9].

MiRNAs are single-stranded, typically 22-nucleotide RNA molecules involved in post-translational silencing of gene expression. They repress mRNA through direct binding to untranslated sequences of the $3^{\prime}$ region of the mRNA [6].

It is worth mentioning that circulating miRNAs are responsible for the transmission of signals between cells and between tissues, and are produced in response to physiological and pathological stimuli as initiators of modulation of gene expression $[5,6]$. It should be emphasized that miRNAs are produced, among others, in connection with DNA methylation, and on the other hand, these molecules may affect the translation of enzymes that catalyze histone modification and DNA methylation [6].

\section{The importance of epigenetic changes} acquired at different development stages for the formation of metabolic disorders Metabolic status of the mother and epigenetic changes in the fetus associated with the risk of developing metabolic and cardiovascular diseases

It is known that external factors affecting the mother's body immediately before conception and during pregnancy may have a lasting effect on the child's 
body. Nutrition of a woman during pregnancy influence the risk of the development of chronic diseases such as type 2 diabetes, obesity and cardiovascular diseases in the offspring [10].

Heijmanset et al. [11] evaluated DNA methylation of peripheral blood cells of individuals whose mothers were exposed to famine around the time of conception, during the Dutch Hunger Winter in 1944-1945. It was found that in the offspring of women who were malnourished during the conception period and early pregnancy IGF2-H19 methylation was reduced by approximately $5 \%$ [11]. Insulin-like growth factor 2 (IGF2) is a protein responsible mainly for the growth of placenta and fetal tissues, but in humans it is also expressed in adulthood. $\mathrm{H} 19$ is extensively transcribed but not translated. Therefore, the product of H19 is a RNA particle, which can act as a suppressor of oncogenesis or affect growth and differentiation processes - alone or with IGF2. During normal development in the early stages of pregnancy, IGF2-H19 undergoes methylation, which results in silencing of IGF2 in the maternal allele, and in $\mathrm{H} 19$-silencing in the paternal allele [12]. The reduction in methylation in people conceived during the Dutch Hunger Winter was observed in adults about 60 years of age. On the one hand, it proves the durability of epigenetic modifications acquired at an early stage of development, but on the other hand, it does not allow ruling out the occurrence of the discussed changes at any stage of life after birth [11]. However, no reduction in DNA methylation was found in the siblings of the examined persons and in the group of the offspring of women who were in the third trimester of pregnancy during the Dutch Hunger Winter - this suggests that epigenetic modifications were acquired at an early stage of prenatal development [11].

Epigenetic modifications were also investigated in a rat model of caloric restriction during pregnancy. Increased activity of histone deacetylases HDAC1 and 4 as well as increase in histone $\mathrm{H} 3$ demethylation were observed in the area of DNA encoding the glucose transporter 4 . These changes are persistent enough that they are still observed in adult animals and may contribute to insulin resistance of skeletal muscles, and consequently to development of type 2 diabetes [13].

It is worth mentioning the results of long-term studies assessing the levels of methylation of over 200 genes in siblings, where older children were born before and younger - after maternal gastrointestinal bypass surgery [14]. In particular, genes regulating carbohydrate metabolism and the insulin-like growth factor 1 (IGF1) cascade were analyzed, the activity of which may lead to the development of type 2 diabetes. Of the genes examined, 6 showed a significant difference in the level of methylation between the groups of siblings born before and after the maternal bariatric surgery, as well as the correlation between methylation, expression and fasting insulinemia. These were the following genes: CD28, CD247, CD3E, HLA-DM beta, HLA-DQ beta 1, and STAT1 [14]. Thus, both mother's exposure to starvation [11] and her excessive obesity [14], can cause permanent epigenetic modifications, consisting in increased or decreased level of DNA methylation.

It should be emphasized that methylation of specific loci may also be caused by hyperglycemia during pregnancy, which occurs in the course of gestational diabetes [10].

Interesting observations were provided by studies evaluating the level of methylation of candidate genes affecting the development of metabolic disorders. The $\angle E P$ gene for leptin and $A D I P O Q$ for adiponectin were considered candidate genes. Leptin causes a decrease in insulin sensitivity, and increased expression of leptin is observed in obesity and diabetes, whereas adiponectin increases insulin sensitivity, has anti-inflammatory and anti-atherosclerotic properties $[15,16]$.

The level of $\angle E P$ and $A D I P O Q$ genes methylation was determined in pregnant women with impaired glucose tolerance, both in maternal and fetal tissues of the placenta. It was found that the maternal insulin resistance index HOMA-IR was inversely related to the $A D I P O Q$ methylation level in the maternal tissues of the placenta. In contrast, maternal glycemia correlated positively with $L E P$ methylation in maternal and negatively with $\angle E P$ and $A D I P O Q$ methylation in the fetal tissues of the placenta. This means that there may be a relationship between epigenetic factors and glucose intolerance in pregnant women. Moreover, maternal gestational diabetes affects the level of methylation of adipokine genes that are crucial for the regulation of fetal metabolism; therefore, different $\angle E P$ and $A D I P O Q$ methylation may have long-term effects that will only appear after birth $[15,16]$.

\section{Intergenerational inheritance of diabetes based on epigenetic mechanisms}

The issue of diabetes inheritance remains unresolved until now. On the one hand, the worldwide increase in the incidence of diabetes in recent years is too large to be attributed to only genetic factors. On the other hand, $50 \%$ of people with type 2 diabetes have a history of this disease also in the immediate family [17].

More than 60 single-nucleotide polymorphisms have been identified that may contribute to the development of type 2 diabetes in specific environmental conditions. However, the effect of each of them is small, and the genetic background of diabetes can be 
satisfactorily justified only in one out of ten patients. Hence, it is suggested that not only classical genetic factors, but rather the epigenetic mechanism may be responsible for the inheritance of diabetes [17].

In a study on the animal model, it was observed that the psychological stress occurring in the F0 (paternal) generation in mice affects the occurrence of carbohydrate disorders in the F1 generation [18]. The offspring of stressed mice are characterized by hyperglycemia caused by increased gluconeogenesis due to overexpression of phosphoenolpyruvate carboxykinase (PEPCK), and the causative factor of PEPCK overexpression in the F1 generation is hypermethylation of the Sfmbt2 gene promoter in the liver and related miR-466b-3p microRNA deficiency, which is a negative regulator of PEPCK expression. Furthermore, these observations suggest that diabetes may develop in the offspring of parents who do not have carbohydrate disorders but are subject to chronic stress [18].

\section{Epigenetic modifications and the course of type 2 diabetes}

The enzymes responsible for the acetylation and deacetylation of histones may affect selected indicators of inflammation [19], which is important for the course of diabetes because type 2 diabetes and obesity are associated with chronic low-grade inflammation observed in many tissues of the patient $[20,21]$. It was observed that HDAC 1, 2 and 3 downregulate the expression of $\mathrm{NF} \kappa \mathrm{B}$ [19], a transcription factor responsible for the activation of the inflammatory process in many intracellular pathways.

Interestingly, both acetyltransferases (HATs) and histone deacetylases (HDACs) are expressed in brain tissue, with HDAC expression changing depending on energy supply [19]. A different profile of deacetylase expression may be the cause of modified expression of genes of the hypothalamus accompanying extreme changes in dietary pattern. The hormones secreted by the hypothalamus in the starvation period including proopiomelanocortin, Aguti neuropeptide and thyreoliberine are of great importance for the regulation of metabolism [22].

Sirtuin 1, a histone deacylase, is regulated by ghrelin. In response to ghrelin stimulation, SIRT1/p53 cascade is activated in the hypothalamus, which stimulates hunger sensation [19]. Another sirtuin, SIRT6, is involved in body growth, glycemic control and obesity development. SIRT6 affects H3 acetylation in various regions of the brain, including those with endocrine functions [19].

Sirtuins are also responsible for the regulation of the transcription of genes affecting hepatic me- tabolism. Caloric restriction and starvation increases histone deacetylation by SIRT1, which is accompanied by the activation of PPAR $\alpha$ and hepatic $X$ receptor and farnesoid $X$ receptor. This results in the improvement of glucose homeostasis and fatty acid oxidation, decrease in lipogenesis, hepatic fatty deposits and inflammation, and in increased cholesterol reuptake $[19,23]$.

Apart from the central nervous system and the liver, HDAC can also modify the function of adipose tissue and pancreas. HDAC 1 and 2 are positive adipogenesis regulators, as evidenced by the fact that their deletion reduces the storage of fat. In contrast, HDAC 9 and SIRT 1 and 2 are negative regulators, because increased expression of HDAC 9, SIRT1 or SIRT2 inhibits differentiation of preadipocytes and reduces adipogenesis, while the deactivation of these deacetylases stimulates differentiation and adipogenesis. SIRT1 increases lipolysis through PPAR $\gamma$ repression, while SIRT2 regulates a number of genes related to adipogenesis, including GLUT4 and a gene for fatty acid synthase [19].

In addition, it was found that one of the histone methyltransferases - a protein containing the SET 7 domain (Set7) - is associated with the secretion of insulin in response to increased glucose level. Namely, Set7 contains a fragment that acts specifically in pancreatic $\beta$-cells and elicits in them a response similar to that caused by a transcription factor specific for the pancreas and $\beta$ cells ( $\mathrm{Pdx} 1$ ). Silencing of Set7 in $\beta$-cells results in impaired mobilization of calcium channels and disturbance of insulin secretion in response to glucose [24]

\section{"Metabolic memory". The importance of epigenetic changes acquired in the course of diabetes for the effectiveness of therapy and the development of late complications}

Many years ago, it has been observed, based on the results of DCCT/EDIC and UKPDS $[25,26]$, that in patients with well-controlled diabetes who had episodes of hyperglycemia in the past there is still a significant risk of developing chronic complications of diabetes, including cardiovascular complications [27, 28].

$A$ retrospective analysis of the data obtained in subsequent clinical trials, such as ACCORD, ADVANCE, VADT and Steno-2, confirmed the so called "legacy effect" observed in the UKPDS study. It turned out that strict control of blood glucose, blood pressure and lipid levels, and anticoagulant therapy were more beneficial for those who did not have significant hyperglycemia or cardiovascular problems before. On the other hand, among participants who already had complications in the cardiovascular system at the time of enrollment 
in the study, strict glycemic control did not bring the expected effects, among others in the reduction of the frequency of micro- and macroangiopathy. Therefore, the condition for effective prevention of diabetes complications should be the early implementation of intensive and multidirectional therapy - early enough to prevent the accumulation of metabolic changes caused by hyperglycemia and hyperlipidemia [29].

The current state of knowledge confirms that the episode of hyperglycemia, followed by a long-lasting period of glycemic normalization, has a lasting effect, essential for the functioning of the body [27], and the phenomenon itself is usually referred to as "metabolic memory". Among other things, it was observed that the hyperglycemia may permanently increase expression of the gene encoding fibronectin, one of the components of the extracellular matrix, the accumulation of which is responsible for a number of renal and cardiac complications in patients with type 2 diabetes [30]. In addition, changes arising from transient hyperglycemia that may lead to cardiovascular complications also include increased production of free radicals and the accumulation of advanced glycation end-products (AGEs) within the mitochondria, cellular lipids, and even nucleic acids [31].

Moreover, there is also an inverse relationship between the periodic occurrence or absence of hyperglycemia and the development of chronic complications of diabetes. It has been proven that intensive insulin therapy administered with an insulin pump and resulting in good glycemic control, even if introduced for a short time and followed by conventional therapy, is associated with a decrease in the incidence of retinopathy, and this effect is statistically significant even after 10 years of treatment [32].

It is believed that the basis for the above described relationships are the epigenetic mechanisms underlying the phenomenon called "metabolic memory" [28]. This hypothesis is supported by the recently published results of the study by Chen et al. [33], in which the level of methylation of selected loci throughout the genome was evaluated among the participants of the EDIC study with an interval of more than 16 years. It was shown that the DNA methylation profile of study participants who were subjected to conventional therapy and who developed retinopathy or microalbuminuria differs from the DNA methylation profile of participants with intensive glycemic control. Only in the conventionally treated group, in which adequate glycemic control was not achieved, persistent hypomethylation of the gene for thioredoxin-responsive protein (TXNIP) was found, the consequence of which may be increased expression of this protein [33].
TXNIP is a pro-apoptotic and prooxidative protein, induced by cellular stress associated with hyperglycemia, and overexpression of TXNIP is associated with the occurrence of diabetic complications. It has also been shown that increased expression of TXNIP also leads to increased post-translational histone modification. This may suggest a direct connection between hyperglycemia, epigenetic DNA modifications within the DNA, and probably also within the histones, and the occurrence of diabetic complications - retinopathy and nephropathy.

Epigenetic regulation determining the formation of metabolic memory includes not only double strand DNA, but also miRNA. Hyperglycemia causes changes in miRNA that result in long-term activation of $\mathrm{NF} \kappa \mathrm{B}$, which persists even after normalization of blood glucose. Due to the simultaneous reduction of SIRT1 expression, $\mathrm{NF} \kappa \mathrm{B}$ predominates in acetylated form. Acetylated $\mathrm{NF} \kappa \mathrm{B}$ interferes with repair processes in the body and affects the interactions between cells [31]. The effects of miRNA modification are long-lasting, because most miRNAs form a complex with the Ago2 protein, resistant both to proteases and nucleases [5].

Epigenetic regulation is therefore important for the development of chronic complications of type 2 diabetes, affecting the prevalence of cardiovascular complications, neuropathy, inflammation and oxidative stress, as well as intercellular communication and repair processes.

Considering the above observations and conclusions, the key question seems to be whether the drugs used to treat diabetes have any effect on epigenetic factors. Metformin, a potent SIRT1 activator, restores disturbed hyperglycemia due to the balance between acetylases and deacetylases. Metformin reverses changes associated with cell aging under hyperglycemic conditions and reduces free radical activation and inflammation. Unfortunately, the protective effect of metformin involves only peripheral tissues, whereas it is not clear whether it also has a beneficial effect on the central nervous system [31].

Another group of drugs that can advantageously modify the course of type 2 diabetes by affecting epigenetic factors are incretin analogs and dipeptidyl peptidase 4 (DPP-4) inhibitors [31]. Endogenous incretins have been shown to reduce the expression of the Fxyd3 gene by methylation of its promoter, and excessive expression of Fxyd 3 observed in type 2 diabetes is associated with a decrease in insulin secretion by $\beta$-cells of the pancreatic islets in response to glucose [34]. It can therefore be assumed that the improvement of $\beta$-cell function in patients with type 2 diabetes observed under the influence of drugs mimicking the action of 
endogenous incretins (analogs) or drugs inhibiting the degradation of native incretins (DPP-4 inhibitors) is largely related to the effect of these drugs on epigenetic factors [31].

It was also observed that fenofibrate, used for the treatment of hypertriglyceridemia in diabetic patients, modifies metabolic memory in a mechanism similar to metformin, causing anti-inflammatory effect, increasing SIRT1 activation and erasing the cellular memory of hyperglycemia [35].

\section{Conclusions}

Epigenetic modifications may affect the phenotype and, consequently, the course of type 2 diabetes. They are not only risk factors for the development and progression of diabetes and its complications, but the knowledge of epigenetics might be used in the future as an element of a personalized therapy of diabetes.

\section{REFERENCES}

1. Deans C, Maggert KA. What do you mean, Genetics. 2015; 199(4): 887-896, doi: 10.1534/genetics.114.173492, indexed in Pubmed: 25855649 .

2. Russo V, Martienssen RA, Riggs AD. Epigenetic Mechanisms of Gene Regulation. Cold Spring Harbor, NY: Cold Spring Harbor Laboratory Press 1996.

3. Probst AV, Dunleavy E, Almouzni G. Epigenetic inheritance during the cell cycle. Nat Rev Mol Cell Biol. 2009; 10(3): 192-206, doi: 10.1038/nrm2640, indexed in Pubmed: 19234478.

4. Jaenisch R, Bird A. Epigenetic regulation of gene expression: how the genome integrates intrinsic and environmental signals. Nat Genet. 2003; 33 Suppl: 245-254, doi: 10.1038/ng1089, indexed in Pubmed: 12610534.

5. Turchinovich A, Weiz L, Langheinz A, et al. Characterization of extracellular circulating microRNA. Nucleic Acids Res. 2011; 39(16): 7223-7233, doi: 10.1093/nar/gkr254, indexed in Pubmed: 21609964.

6. Chuang JC, Jones PA. Epigenetics and microRNAs. Pediatr Res. 2007; 61 (5 Pt 2): 24R-29R, doi: 10.1203/pdr.0b013e3180457684, indexed in Pubmed: 17413852.

7. McGee SL, Hargreaves M. Histone modifications and exercise adaptations. J Appl Physiol (1985). 2011; 110(1): 258-263, doi: 10.1152/japplphysiol.00979.2010, indexed in Pubmed: 21030677.

8. Cencioni C, Spallotta F, Martelli F, et al. Oxidative stress and epigenetic regulation in ageing and age-related diseases. Int J Mol Sci. 2013; 14(9): 17643-17663, doi: 10.3390/ijms140917643, indexed in Pubmed: 23989608.

9. Klose RJ, Bird AP. Genomic DNA methylation: the mark and its mediators. Trends Biochem Sci. 2006; 31(2): 89-97, doi: 10.1016/j. tibs.2005.12.008, indexed in Pubmed: 16403636.

10. El Hajj $N$, Schneider $E$, Lehnen $H$, et al. Epigenetics and life-long consequences of an adverse nutritional and diabetic intrauterine environment. Reproduction. 2014; 148(6): R111-R120, doi: 10.1530/REP-14-0334, indexed in Pubmed: 25187623.

11. Heijmans BT, Tobi EW, Stein AD, et al. Persistent epigenetic differences associated with prenatal exposure to famine in humans. Proc Natl Acad Sci U S A. 2008; 105(44): 17046-17049, doi: 10.1073/pnas.0806560105, indexed in Pubmed: 18955703.

12. Nordin M, Bergman D, Halje M, et al. Epigenetic regulation of the Igf2/H19 gene cluster. Cell Prolif. 2014; 47(3): 189-199, doi: 10.1111/cpr.12106, indexed in Pubmed: 24738971.

13. Raychaudhuri N, Raychaudhuri S, Thamotharan M, et al. Histone code modifications repress glucose transporter 4 expression in the intrauterine growth-restricted offspring. J Biol Chem. 2008; 283(20): 13611-13626, doi: 10.1074/jbc.M800128200, indexed in Pubmed: 18326493.

14. Guénard F, Deshaies Y, Cianflone K, et al. Differential methylation in glucoregulatory genes of offspring born before vs. after maternal gastrointestinal bypass surgery. Proc Natl Acad Sci U S A. 2013; 110(28): 11439-11444, doi: 10.1073/pnas.1216959110, indexed in Pubmed: 23716672.

15. Bouchard L, Thibault S, Guay SP, et al. Leptin gene epigenetic adaptation to impaired glucose metabolism during pregnancy. Diabetes Care. 2010; 33(11): 2436-2441, doi: 10.2337/dc101024, indexed in Pubmed: 20724651.

16. Bouchard L, Hivert MF, Guay SP, et al. Placental adiponectin gene DNA methylation levels are associated with mothers' blood glucose concentration. Diabetes. 2012; 61(5): 1272-1280, doi: 10.2337/db11-1160, indexed in Pubmed: 22396200.

17. Rathmann W, Scheidt-Nave C, Roden M, et al. Type 2 diabetes: prevalence and relevance of genetic and acquired factors for its prediction. Dtsch Arztebl Int. 2013; 110(19): 331-337, doi: 10.3238/arztebl.2013.0331, indexed in Pubmed: 23762204.

18. Wu L, Lu Y, Jiao Y, et al. Paternal Psychological Stress Reprograms Hepatic Gluconeogenesis in Offspring. Cell Metab. 2016; 23(4): 735-743, doi: 10.1016/j.cmet.2016.01.014, indexed in Pubmed: 26908462.

19. Iyer A, Fairlie DP, Brown L. Lysine acetylation in obesity, diabetes and metabolic disease. Immunol Cell Biol. 2012; 90(1): 39-46, doi: 10.1038/icb.2011.99, indexed in Pubmed: 22083525.

20. Gregor MF, Hotamisligil GS. Inflammatory mechanisms in obesity. Annu Rev Immunol. 2011; 29: 415-445, doi: 10.1146/annurevimmunol-031210-101322, indexed in Pubmed: 21219177.

21. Shoelson SE, Lee J, Goldfine $A B$. Inflammation and insulin resistance. J Clin Invest. 2006; 116(7): 1793-1801, doi: 10.1172/ $/ \mathrm{JCl} 29069$, indexed in Pubmed: 16823477.

22. Funato H, Oda S, Yokofujita J, et al. Fasting and high-fat diet alter histone deacetylase expression in the medial hypothalamus. PLoS One. 2011; 6(4): e18950, doi: 10.1371/journal.pone.0018950, indexed in Pubmed: 21526203.

23. Schug TT, Li X. Sirtuin 1 in lipid metabolism and obesity. Ann Med. 2011; 43(3): 198-211, doi: 10.3109/07853890.2010.547211, indexed in Pubmed: 21345154.

24. Siebel AL, Fernandez AZ, El-Osta A. Glycemic memory associated epigenetic changes. Biochem Pharmacol. 2010; 80(12): 1853-1859, doi: 10.1016/j.bcp.2010.06.005, indexed in Pubmed: 20599797.

25. Lachin JM, Genuth S, Cleary P, et al. Diabetes Control and Complications Trial/Epidemiology of Diabetes Interventions and Complications Research Group. Retinopathy and nephropathy in patients with type 1 diabetes four years after a trial of intensive therapy. N Engl J Med. 2000; 342(6): 381-389, doi: 10.1056/ /NEJM200002103420603, indexed in Pubmed: 10666428.

26. Tight blood pressure control and risk of macrovascular and microvascular complications in type 2 diabetes: UKPDS 38. UK Prospective Diabetes Study Group. BMJ. 1998; 317(7160): 703-713, doi: 10.1136/bmj.317.7160.703, indexed in Pubmed: 9732337.

27. Cencioni C, Spallotta F, Greco S, et al. Epigenetic mechanisms of hyperglycemic memory. Int J Biochem Cell Biol. 2014; 51: 155-158, doi: 10.1016/j.biocel.2014.04.014, indexed in Pubmed: 24786298.

28. Brasacchio D, Okabe J, Tikellis C, et al. Hyperglycemia induces a dynamic cooperativity of histone methylase and demethylase enzymes associated with gene-activating epigenetic marks that coexist on the lysine tail. Diabetes. 2009; 58(5): 1229-1236, doi: 10.2337/db08-1666, indexed in Pubmed: 19208907.

29. Bianchi C, Del Prato S. Metabolic memory and individual treatment aims in type 2 diabetes - outcome-lessons learned from large clinical trials. Rev Diabet Stud. 2011; 8(3): 432-440, doi: 10.1900/RDS.2011.8.432, indexed in Pubmed: 22262079.

30. Roy S, Sala R, Cagliero E, et al. Overexpression of fibronectin induced by diabetes or high glucose: phenomenon with a memory. Proc Natl Acad Sci U S A. 1990; 87(1): 404-408, doi: 10.1073/ /pnas.87.1.404, indexed in Pubmed: 2296596. 
31. Berezin A. Metabolic memory phenomenon in diabetes mellitus: Achieving and perspectives. Diabetes Metab Syndr. 2016; 10 (2 Suppl 1): S176-S183, doi: 10.1016/j.dsx.2016.03.016, indexed in Pubmed: 27025794.

32. Nathan DM, Genuth S, Lachin J, et al. Diabetes Control and Complications Trial Research Group. The effect of intensive treatment of diabetes on the development and progression of long-term complications in insulin-dependent diabetes mellitus. N Engl J Med. 1993; 329(14): 977-986, doi: 10.1056/ /nejm199309303291401, indexed in Pubmed: 8366922.

33. Chen Z, Miao F, Paterson AD, et al. DCCT/EDIC Research Group. Epigenomic profiling reveals an association between persistence of DNA methylation and metabolic memory in the DCCT/EDIC type 1 diabetes cohort. Proc Natl Acad Sci U S A. 2016; 113(21): E3002-E3011, doi: 10.1073/pnas.1603712113, indexed in Pubmed: 27162351.

34. Vallois D, Niederhäuser G, Ibberson $M$, et al. Gluco-incretins regulate beta-cell glucose competence by epigenetic silencing of Fxyd3 expression. PLoS One. 2014; 9(7): e103277, doi: 10.1371/ /journal.pone.0103277, indexed in Pubmed: 25058609.
35. Zhao S, Li J, Wang Na, et al. Fenofibrate suppresses cellular metabolic memory of high glucose in diabetic retinopathy via a sirtuin 1-dependent signalling pathway. Mol Med Rep. 2015; 12(4): 6112-6118, doi: 10.3892/mmr.2015.4164, indexed in Pubmed: 26238659.

36. Sterner DE, Berger SL. Acetylation of histones and transcription-related factors. Microbiol Mol Biol Rev. 2000; 64(2): 435-459, indexed in Pubmed: 10839822.

37. Wegner M, Pioruńska-Stolzmann M, Jagodziński PP. Wpływ modyfikacji struktury chromatyny na rozwój przewlekłych powikłań cukrzycowych. Postepy Hig Med Dosw (Online). 2015; 69: 964-968, doi: 10.5604/17322693.1165198, indexed in Pubmed: 26400882.

38. Chen M, Zhang L. Epigenetic mechanisms in developmental programming of adult disease. Drug Discov Today. 2011; 16(23-24): 1007-1018, doi: 10.1016/j.drudis.2011.09.008, indexed in Pubmed: 21945859.

39. Seto $E$, Yoshida M. Erasers of histone acetylation: the histone deacetylase enzymes. Cold Spring Harb Perspect Biol. 2014; 6(4): a018713, 1-26, doi: 10.1101/cshperspect.a018713, indexed in Pubmed: 24691964. 